\title{
Modelling and Design of a Smart Prototype Garage Door
}

\author{
Israel Enema Ohiemi ${ }^{1}$, Nwokolo Tochukwu ${ }^{1}$, Anyaoha Chukwuemeka ${ }^{1}$, Kolo Yetu Babazhitsu', ${ }^{2, *}$ \\ Enock Ojo Israel $^{2}$, Wodi Chibeoso ${ }^{1}$, Chibuzo Nwokolo ${ }^{1}$, Ayuba Elkanah Jatau ${ }^{3}$ \\ ${ }^{1}$ Department of Mechanical Engineering, University of Nigeria, Nsukka, Nigeria. \\ ${ }^{2}$ Department of Mechanical Engineering, Federal Polytechnic Bida, Niger State, Nigeria. \\ ${ }^{3}$ Department of Mechanical Engineering Technology, Niger State Polytechnic, Zungeru, Nigeria.
}

How to cite this paper: Israel Enema Ohiemi, Nwokolo Tochukwu, Anyaoha Chukwuemeka, Kolo Yetu Babazhitsu, Enock Ojo Israel, Wodi Chibeoso, Chibuzo Nwokolo, Ayuba Elkanah Jatau. (2022) Modelling and Design of a Smart Prototype Garage Door. Engineering Advances, 2(1), 26-35.

DOI: $10.26855 /$ ea.2022.06.003

Received: December 28, 2021

Accepted: January 25, 2022

Published: March 3, 2022

*Corresponding author: Kolo Yetu Babazhitsu, Department of Mechanical Engineering, Federal Polytechnic Bida, Niger State, Nigeria.

Email: yetukolo@gmail.com

\begin{abstract}
The focus of this paper is to design and model a smart garage door while demonstrating how its contraption works. A prime mover (a stepper motor) is attached to the mechanical system. The system is automated by the use of ESP32 microcontroller containing a Wi-Fi module. It also serves as the interface between the software and the hardware parts of the system. The software part of the system is embedded within the ESP32 microcontroller and is accessed with a smartphone. The smartphone screen serves as the Graphical User Interface (GUI) between the Arduino codes and the hardware. Commands are sent through the smartphone whose hotspot system is connected to the ESP32's Wi-Fi, the ESP32 then controls the switches through a series of relays and the door opens or closes at the user's convenience. The design is tested and demonstrated with a prototype of a garage door built from easily obtained materials; plywood and plastic. A rack and pinion arrangement was used in the design. On testing the Wi-Fi range, about $600 \mathrm{~m}$ was obtained for outdoor testing without barriers while $45 \mathrm{~m}$ was obtained for indoor testing in the presence of barriers.
\end{abstract}

\section{Keywords}

ESP32 microcontroller, Wi-Fi module, graphical User Interface (GUI), garage door, prototype

\section{Introduction}

The design of garage doors has evolved over time, dating from the time of barn and stable doors. Modern garage doors are meant to minimize human effort is used while opening them. This design was carried out to enable end users, open their garage doors from the comfort of their cars without the need to exit the car. The comfort that stems from this technology is attractive especially to individuals living alone. To achieve the above, automation is adopted. Automation is the utilization of means void of man's inputs to actualize a task. It is the arraignment of tools or machines in ways to limit or eliminate human intervention. The field of automation keeps growing by the day, and due to much work, which has been put into this field, it has become cheaper and thus very popular.

The designed system is equipped with a ESP32 micro-controller and hence operate in a simple manner. ESP32 micro-controller embedded with Wi-Fi module which enhances its connectivity to smart phone device. For adequate security, the hotspot from the transmitting device is passworded and only allows designated users access. The user logs into a web address which provides a graphic user interface to gain full control of the garage door.

Numerous research effort has been made on smart garage door [1], presented the design and fabrication of an automatic gate using Arduino. Lehr and Benson [2], executed a project which concentrated on the structure leading to the establishment of minimal effort framework by screening the garage door entry ways and transmitting their status to a 
receiver. Kiran et al. [3] proposed a system which uses an Infrared sensor to sense the movement of human body near the door. The human body radiates infrared energy as heat; the PIR sensor detects this infrared energy from a certain distance. Ahmed et al. [4] carried out a design for an automated garage door which used vehicle license number recognition to control the door. Aman [5] carried out a project to design optimum electromechanical parts which would be attached to existing garage door designs. Oladunmoye et al. [6] presented a research work of an automatic sliding entryway system utilizing an infrared sensor. Irmak et al. [7] used programmable logic controller (PLC) to establish a garage door which use a computer interactive smart home system. Zungeru and Attah [8] carried out a design to model and design an automatic sliding door with a room light control system to automate the process of closing and opening the door. Patil et al. [9] carried out a study which deals with designing and implementing of Secure Locking Automation using Raspberry Pi for unlocking doors so as to increase the security in homes, bank lockers and other related control operations. The authors above used several methods to design and implement a smart garage door. However, in this paper, an attempt would be made to design an automated garage door using ESP32 incorporated with a Wi-Fi module. Furthermore, a proto-type of the design was built, automated and tested.

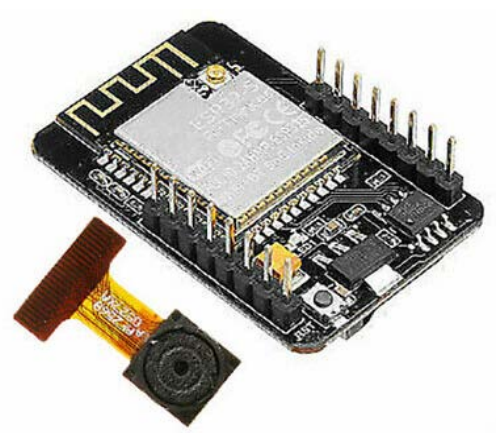

Figure 1. ESP32 microcontroller [10].

The ESP 32 is a low-cost micro-controller with onboard Bluetooth and Wi-Fi module. For the purposes of the design, only the Wi-Fi module would be used. This microcontroller is powered by the 5 volts output from the voltage regulator. The micro-controller has an onboard 3.3-volt regulator to regulate the voltage to the value required by the chip (3.3 volts).

The ESP 32 is used as a web server that serves an html user interface to control the stepper motor attached to the micro-controller. The IP of the ESP32 server is 192.168.43.191. Once the ESP32 is powered on, the ESP32 connect to the hotspot already programmed. The server then listens on port 80 for any http request using the URL 192.168.43.191

Once an http request is made, say from a mobile browser to the above URL, the server serves the control page to the client's browser. The user can then control the motor attached to the ESP32 using the interface served up in the browser. The available control is shown in Figure 2.

\section{OPEN}

\section{CLOSE}

Figure 2. The Graphical User Interface of system.

The ESP32 micro-controller serves as the interface between the software and the hardware of the whole system. The ESP32 will work with the Smart phone through the written ESP32 code. The system is split into three basic parts as shown in Figure 3.

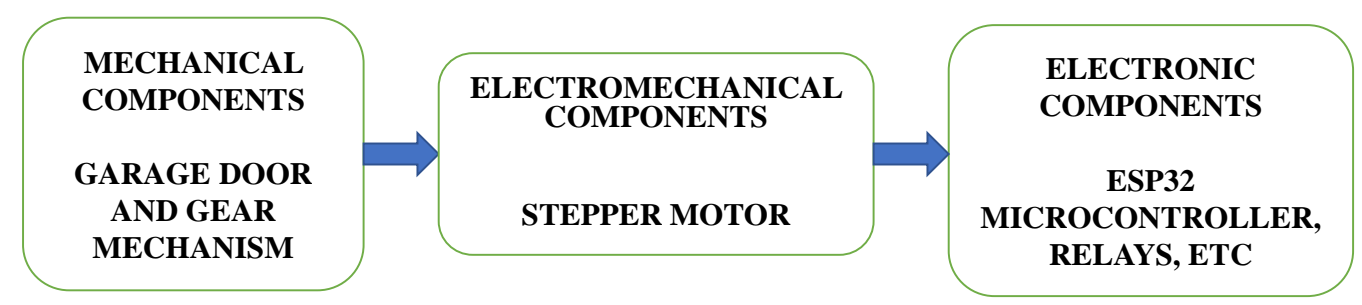

Figure 3. Summary of the system components. 


\section{Materials}

\subsection{Rack and Pinion Mechanism}

The rack and pinion mechanism is a substantial part of the design of a smart garage door. They were fabricated from plastic because it light and smooth and thus makes for easier meshing.

\subsection{Garage Door and Door Frame}

The garage door and its frame are important components and requires a careful choice of appropriate material. As a result, for the construction of this prototype, plywood was selected for both the garage door and its corresponding frame due to its low cost, availability and workability.

\subsection{L293D stepper motor driver}

The output of the ESP 32 is only 3.3 volts and cannot drive the 12 volts' stepper motor used in the project. Therefore, a voltage driver is used. The L293D is a high current motor driver capable of driving a maximum load rating of 36 volts. Therefore, the logic outputs of the ESP32 are connected to driver circuit. The ESP 32 pins GPIO pins GPIO14 GPIO16 GPIO17 GPIO18 are connected to the input pins 1, 2, 3, and 4 of the L293D driver. The required output of 12 volts is outputted to the stepper motor leads attached to the output pins 1, output 2, output 3 and output 4 of the L293D driver.

\subsection{HS8401 stepper Motor}

The 17HS8401 stepper motor was used in the project to open or close the garage door based on the input received from the user interface shown in Figure 1. A stepper motor can either be used in the bipolar or the unipolar mode of operation.

The unipolar stepper motor operates with a single winding with a center tap for each phase. Every section of the winding turns for any particular direction of the magnetic field. Each of the windings is relatively simplified with the commutation circuit; this is because the arrangement has a reversible magnetic pole which can be done without changing the direction of the current. In most cases, given a phase, the common center tap for each winding is the following; three leads for each phase and six leads for a normal two-phase stepper motor.

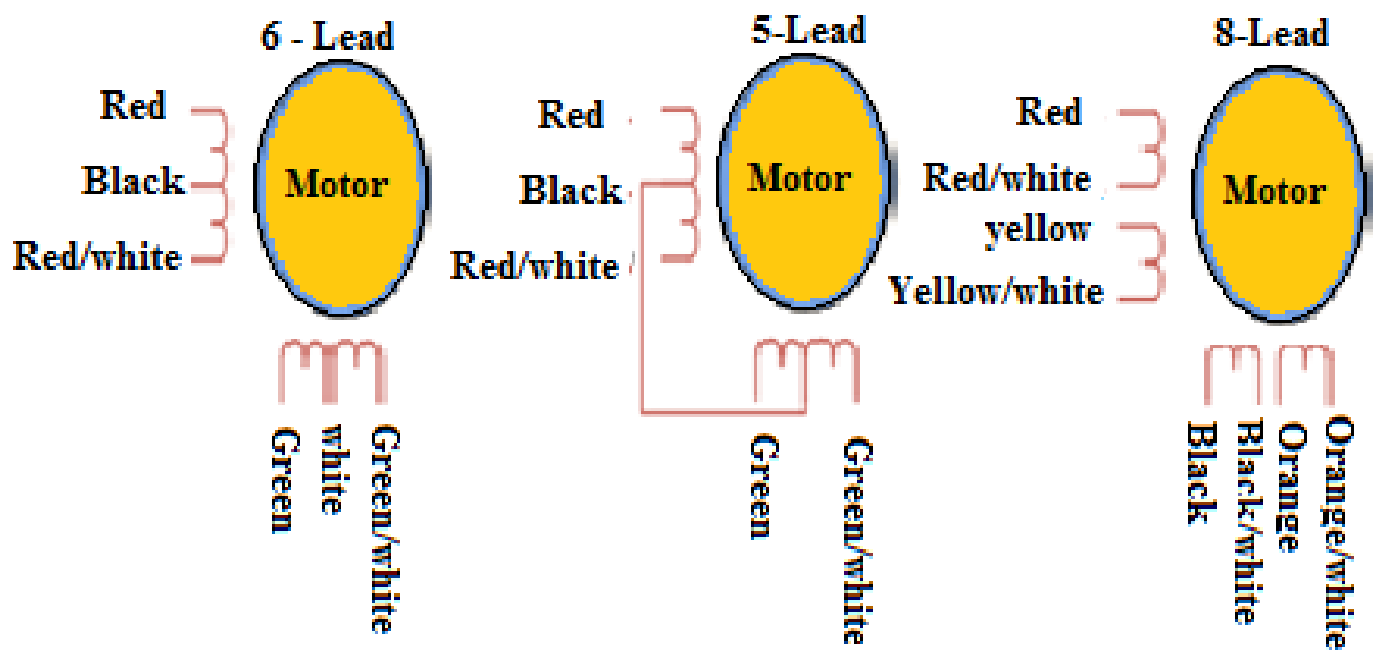

Figure 4. Unipolar stepper motor.

A single winding per phase is the characteristics of a bipolar stepper motors has only a single winding per phase. Unlike the unipolar stepper motor, the bipolar stepper motor has two leads per phase, neither of which is common. Bipolar motors are generally better than unipolar motors. They have more torque and are more efficient. The 17HS8401 stepper motor was used in bipolar mode in the project. The outputs of the L293D driver are connected the 4 inputs of the stepper motor.

For bipolar stepper motors, there is only a single winding per phase. Unlike the unipolar stepper motor, the bipolar stepper motor has two leads per phase, neither of which is common. Bipolar motors are generally better than unipolar 
motors. They have more torque and are more efficient. The 17HS8401 stepper motor was used in bipolar mode in the project. The outputs of the L293D driver are connected the 4 inputs of the stepper motor.

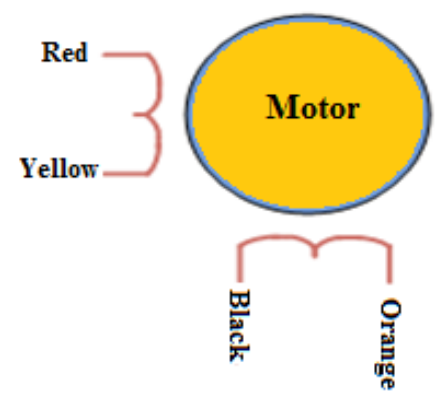

Figure 5. Bipolar stepper motor.

\section{Method}

The conceptual designs started with preliminary sketches of the perceived components bearing in mind the required operations of the component assembly and how the objectives would be actualized. Rough sketches were made and designs which were not feasible were discarded until a more feasible design (the sliding door system, moved by a rack and pinion gear system) was actualized. The design process involved a detailed Computer Aided Design (CAD) drawing of individual components that make up the whole system as shown in Figure 8. The CAD software used was Autodesk Inventor.

The analysis was done using the mathematical tools and the Autodesk Inventor program. A static analysis of the pinion was made using the Autodesk software; different loads were applied on the simulation to check the maximum load before deformation.

The individual components as described above were fabricated or assembled as the case maybe; the proposed method is the use of plywood to fabricate the mechanical parts. Another part of the fabrication process also involves the acquisition of the different equipment which will be used for moving and controlling of the mechanical system. The acquired components include; the stepper motor (the prime mover), the ESP32 (incorporating an Arduino board and a Wi-Fi module) and the transformer. The android software was also written using the Android Studio program and this software together with theESP32 Wi-Fi module would bring about the system's automation.

\subsection{Circuit Operation Summary}

Once the ESP 32 is powered on, the server code running on the ESP32 connects to the hotspot via Wi-Fi. The password and username of the hotspot were programmed into the ESP32. The server code then listens on port 80 for any http request to the URL; 192.168.43.191/. Once a user browses the URL, the ESP 32 serves up the user interface to the user's browser. The User can then control the motor attached to the ESP32 via the Open and Close button in the user interface.

Because the ESP 32 cannot directly drive the 12 volts' stepper motor, the L293D motor driver was used in the project to provide the stepper motor with the required 12 volts. The automation circuit diagram is shown in Figure 6 below.

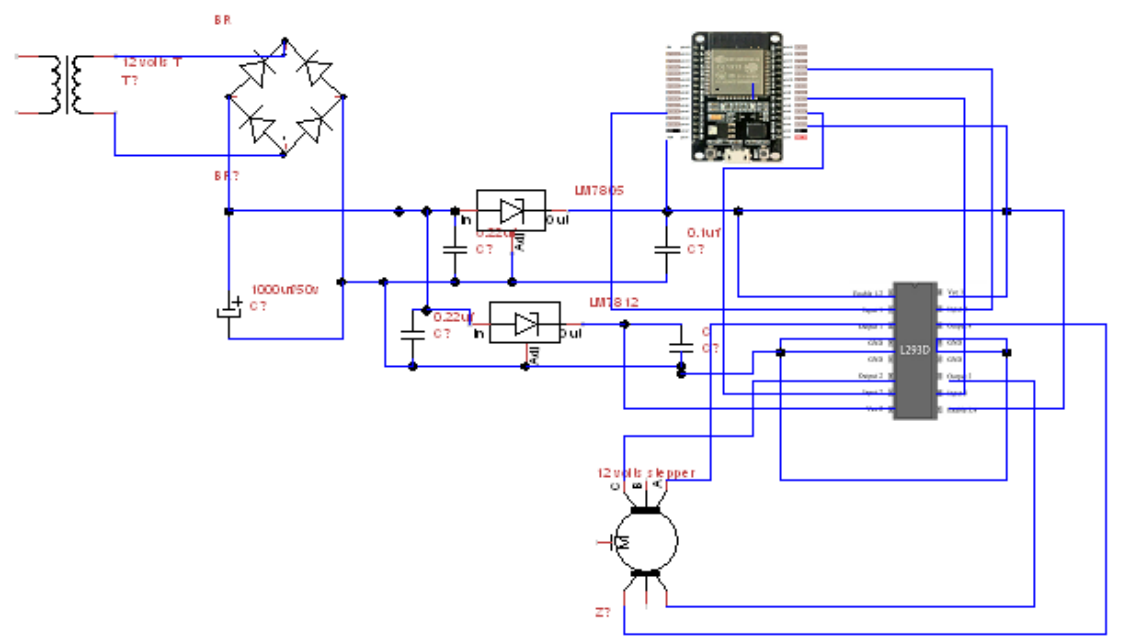

Figure 6. Circuit diagram for the system. 


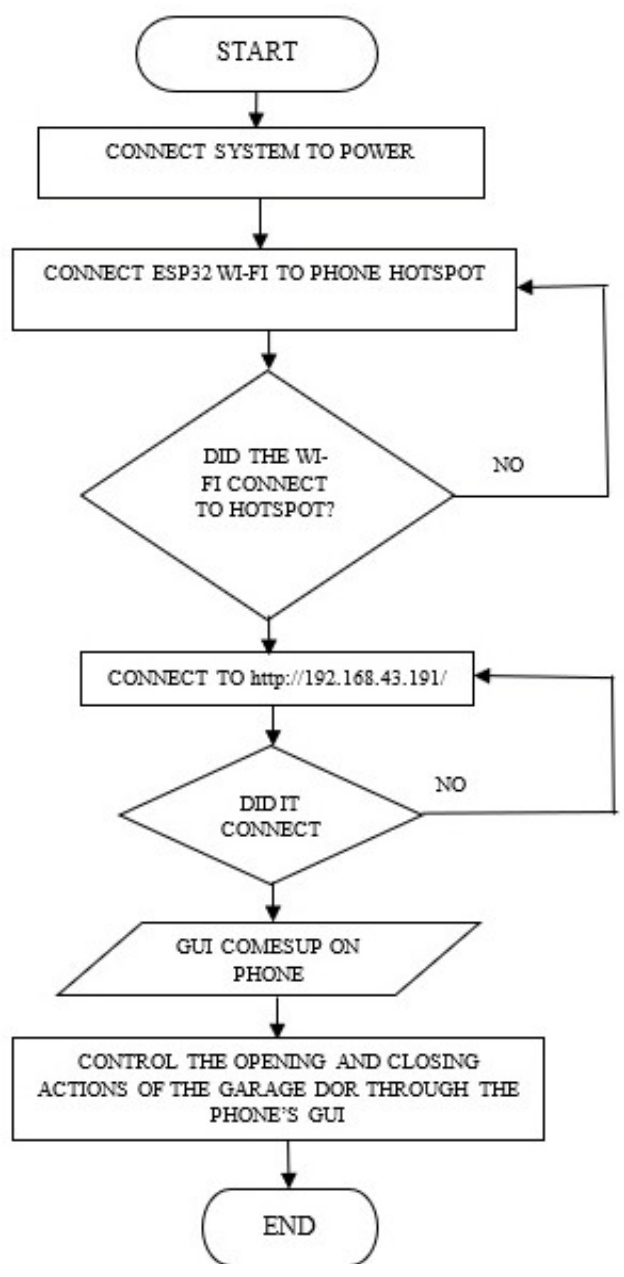

Figure 7. Flowchart of the algorithm used for system control.

\subsection{The ESP32 Server Code}

The smart phone control which is used to remotely control the garage door is an android code which was written using the Android Studio IDE. A code snippet is shown in appendix A

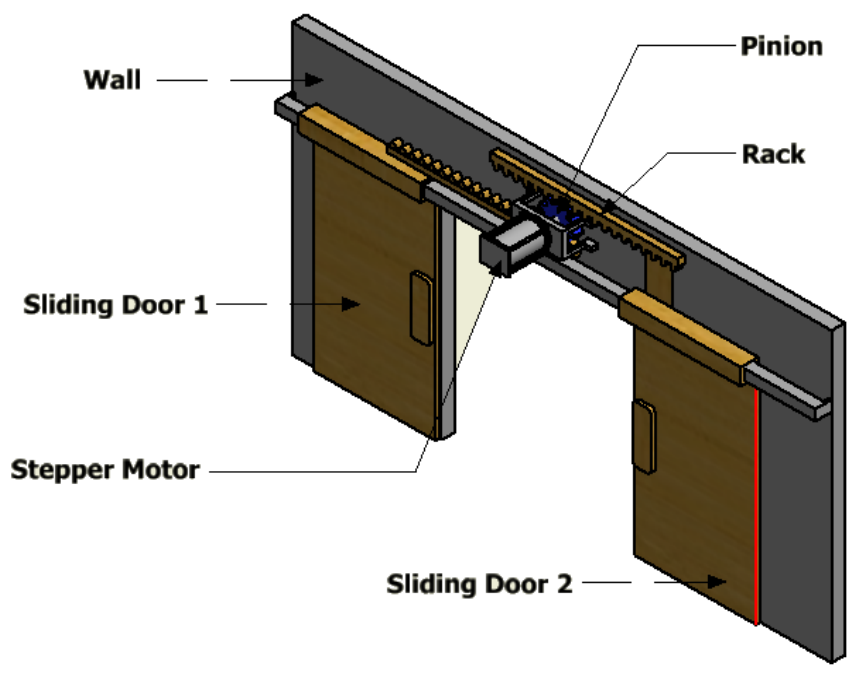

Figure 8. 3D CAD Model of the system. 


\subsection{Design Calculations}

In this section, we want to determine the power relationships in our system. From the previous sections, it was made clear that the garage door was conceptualized bearing mind a door which would have the capacity of a Range Rover Sport SUV. The Range Rover Sport SUV has the following dimensions: Length: 188.3 inches or 4,783mm, Width: 76.1inches or $1,933 \mathrm{~mm}$, Height: 71.5 inches or $1,816 \mathrm{~mm}$. From the above, a garage door with the dimensions of $80 \times 75$ inches was chosen. $A=\pi r^{2}$

\subsubsection{Power Calculations}

We want to determine the power required to pull the door. This would be the power to be transmitted to the gear.

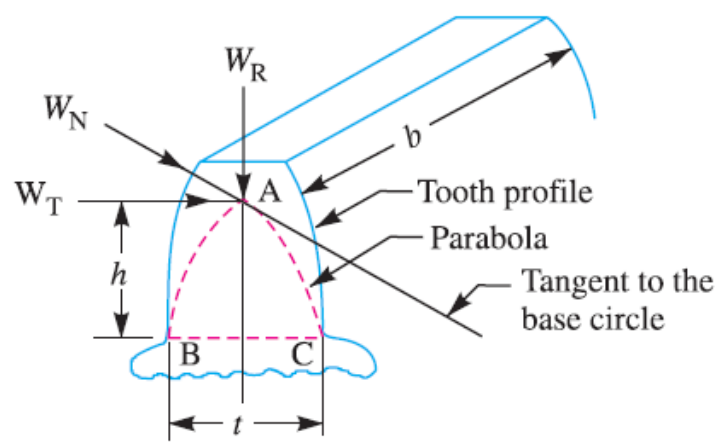

Figure 9. Tooth of a gear.

The steady load due to torque transmission is evaluated with equation (1):

$$
W_{T}=\frac{P}{v} \times C_{S}
$$

From the above, we see that power transmitted $P$ is:

$$
P=\frac{W_{T} \times v}{C_{s}}
$$

Where: $W_{T}=$ steady load due to transmitted torque

$$
\begin{array}{r}
C_{s}=\text { service factor, } \quad \text { from tables } \ldots, C_{s}=1 \\
v=\text { pitch line velocity; } \frac{\pi D N}{60}
\end{array}
$$

Also, we know that $W_{T}=\sigma_{w} \times b \times t^{2} / \sigma h$

Where; $\sigma_{w}=$ is the beam strength of the gear tooth which is used to determine the load carrying capacity of the gear. From Lewis equation;

$$
\sigma_{w}=M \cdot y / I
$$

Where; $M=$ maximum bending moment at the critical point,

$$
\mathrm{BC}=W_{T} \times h
$$

$y=$ half the thickness of the tooth at critical section $\mathrm{BC}=t / 2$

$I=$ moment of inertia about the center-line of the tooth; $b \cdot t^{3} / 12$

So,

$$
W_{T}=\sigma_{w} \cdot b \cdot P_{c} \cdot y
$$

Where; $P_{c}$ is the circular pitch and is the distance measured from the point of one tooth to the corresponding point on the next.

$$
P_{c}=\frac{\pi D}{T}
$$

$D=$ Diameter of pitch circle

$T=$ Number of teeth on the wheel 
Also, $W_{T}=\sigma_{w} \cdot b \cdot \pi \cdot m \cdot y$, where

$m=$ module is the ratio of the pitch circle diameter in millimeters to the number of teeth

Since power, $P=\frac{W_{T} \times v}{C_{s}}$ and $C_{s}=1$, so $P=W_{T} \times v$

Then: Power, $P=\sigma_{w} \cdot b \cdot P_{c} \cdot y \cdot v$

Where, $v=$ velocity

And $\sigma_{w}=\sigma_{o} \times C_{v}$

$\sigma_{o}=$ allowable static stress and for medium grade cast iron, $\sigma_{o}=70 \mathrm{MPa}$

$C_{v}=$ velocity factor, for ordinary cut gears operating at velocities up to $12.5 \mathrm{~m} / \mathrm{s}$;

Assuming our garage door moves at a velocity of $0.5 \mathrm{~m} / \mathrm{s}$ :

$$
\begin{gathered}
C_{v}=\frac{3}{3+v}=\frac{3}{3+0.5}=\frac{3}{3+v}=\frac{3}{3.5}=0.8571 \\
\sigma_{o}=70 \mathrm{~N} / \mathrm{mm}^{2} . \\
\sigma_{w}=\sigma_{o} \times C_{v}=70 \times 0.8571=26.25 \mathrm{~N} / \mathrm{mm}^{2}
\end{gathered}
$$

Module,

$$
m=\frac{D}{T}
$$

$D=$ Pitch circle diameter $=2.425 \times 25.4=61.314 \mathrm{~mm}$

$T=$ Number of teeth $=12$

$$
m=\frac{61.314}{12}=5.11175 \mathrm{~mm} / \text { tooth }
$$

$0.124-\frac{0.684}{T}$ for $14 \frac{1}{2}^{\circ}$ composite and full depth involute system.

$$
\begin{gathered}
0.124-\frac{0.684}{12}=0.067 \text { per teeth } \\
\text { face width } b=3 P_{c} \\
b=3 \times \pi \times \frac{D}{T}=3 \times \pi \times 5.1175 \\
b=48.18 \mathrm{~mm} / \text { teeth }=0.0482 \mathrm{~m} / \text { teeth } \\
P=\sigma_{w} \cdot b . P_{c} \cdot y \cdot v=\frac{60 \mathrm{~N}}{\mathrm{~mm}^{2}} \times 48.18 \mathrm{~mm} \times \pi \times 5.11 \mathrm{~mm} \times 0.067 \times \frac{0.5 \mathrm{~m}}{\mathrm{~s}}=1555.089 \mathrm{Watts} \text { or } 1.56 \mathrm{KW} \\
746 \mathrm{Watts}=1 \mathrm{hp} \\
1555.089 \mathrm{Watts}=2.08 \mathrm{hp}
\end{gathered}
$$

\subsubsection{Dynamic Tooth Load Calculations}

The dynamic tooth load is calculated using the Buckingham equation

$$
W_{D}=W_{T}+W_{I}
$$

Where $W_{D}=$ total dynamic load

But, $W_{I}=\frac{21 v\left(b . C+W_{T}\right)}{21 v+\sqrt{b \cdot C+W_{T}}}$

$$
\begin{aligned}
& W_{T}=\text { steady load due to transmitted torque } \\
& W_{I}=\text { increment load due to dynamic action }
\end{aligned}
$$

Where:

$$
\begin{gathered}
v=\text { pitch line velocity in } \mathrm{m} / \mathrm{s} \\
b=\text { face width of gear in } \mathrm{mm} \\
C=\text { deformation or dynamic factor in } \mathrm{N} / \mathrm{mm}^{2} \\
C \text { is obtained by interpolation from tables }
\end{gathered}
$$

So, 


$$
\begin{gathered}
W_{D}=W_{T}+\frac{21 v\left(b . C+W_{T}\right)}{21 v+\sqrt{b . C+W_{T}}} \\
W_{T}=\frac{P}{v}
\end{gathered}
$$

Where:

$$
\begin{gathered}
P=\text { power in watts } \\
v=\text { velocity in } \mathrm{m} / \mathrm{s} \\
\rightarrow W_{T}+\frac{3.110}{0.5}=6.22 \mathrm{~N}
\end{gathered}
$$

So:

$$
W_{I}=\frac{21 \times 0.5 \times(48.18 \times 165+6.22)}{21 \times 0.5+\sqrt{48.18 \times 165+6.22}}
$$

\subsubsection{Static Tooth Load Calculations}

$$
W_{S}=\sigma_{e} \cdot b \cdot P_{c} \cdot y=\sigma_{e} \cdot b \cdot \pi \cdot m \cdot y
$$

Where:

$$
\begin{gathered}
W_{S}=\text { static tooth load } \\
\sigma_{e}=\text { flexural endurance limit } \\
b, P_{c}, \quad m \text { and y are as previously defined }
\end{gathered}
$$

For cast iron, $\sigma_{e}=84 \mathrm{MPa}$

$$
\begin{gathered}
W_{S}=84 \mathrm{~N} / \mathrm{mm}^{2} \times 48.18 \mathrm{~mm} \times \pi \times 5.11 \mathrm{~mm} \times 0.067 \\
W_{S}=4354.52 \mathrm{~N}
\end{gathered}
$$

\subsubsection{Wear Tooth Load Calculations}

The wear tooth load is given by the expression:

$$
W_{w}=D_{P} \cdot b \cdot Q \cdot K
$$

Where:

$$
\begin{gathered}
W_{w}=\text { maximum or limiting load for wear in newtons } \\
D_{P}=\text { pitch circle diameter of the pinion in } \mathrm{mm} \\
b=\text { face width of the pinion in } \mathrm{mm} \\
Q=\text { ratio factor } \\
Q=\frac{2 \times V \cdot R}{V \cdot R+1}=\frac{2 T_{G}}{T_{G}+T_{P}} \text { for external gears } \\
Q=\frac{2 \times V \cdot R}{V \cdot R-1}=\frac{2 T_{G}}{T_{G}-T_{P}} \text { for internal gears }
\end{gathered}
$$

Where:

$$
\begin{gathered}
V . R=\text { velocity ratio }=\frac{T_{G}}{T_{P}} \\
T_{G}=\text { number of teeth on gear }=20 \text { teeth } \\
T_{P}=\text { number of teeth on pinion }=10 \text { teeth } \\
Q=\frac{2 \times 20}{10+20}=\frac{40}{30}=1.33 \dddot{3} \\
K=\text { load }- \text { stress factor in } \mathrm{N} / \mathrm{mm}^{2}
\end{gathered}
$$

( $K$ is also known as material combination factor) 


$$
\begin{gathered}
K=\frac{\left(\sigma_{e s}\right)^{2} \sin \varphi}{1.4}\left[\frac{1}{E_{P}}+\frac{1}{E_{G}}\right] \\
\sigma_{e s}=\text { surface endurance limit in } M P a \\
\varphi=\text { pressure angle }
\end{gathered}
$$

$$
\begin{gathered}
E_{P}=\text { Young's modulus for the material of the pinion in } \mathrm{N} / \mathrm{mm}^{2} \\
E_{G}=\text { Young's modulus for the material of the gear in } \mathrm{N} / \mathrm{mm}^{2}
\end{gathered}
$$

$$
\begin{gathered}
\sigma_{e s}=630 \mathrm{~N} / \mathrm{mm}^{2} \text { (for grey cast iron) } \\
E_{P}=170 \mathrm{GPa} \\
E_{G}=170 \mathrm{GPa} \\
K=\frac{(630)^{2} \sin 14.5}{1.4}\left[\frac{1}{170 \times 10^{3}}+\frac{1}{170 \times 10^{3}}\right] \\
K=0.835 \mathrm{~N} / \mathrm{mm}^{2} \\
W_{w}=61.341 \times 48.18 \times 1.33 \times 0.835 \\
W_{w}=3281.93 \mathrm{~N}
\end{gathered}
$$

(from tables, $K=0.107$ for pressure angle of $14 \frac{1}{2}^{\circ}$ and $W_{w}$ is obtained as $420.56 N$ )

\section{Performance Evaluation}

The performance evaluation of the smart garage door was done in two major ways; testing the range of the nWi-Fi module and comparing it with other long range devices and efficiency test. There are many different methods of wireless transmission which includes, but not restricted to, Infrared, Bluetooth and Wi-Fi. These different methods of transmission have their own different ranges. In this project, the range of the Wi-Fi module is compared with the range of the other two methods listed so as to determine which method is best suited for the task at hand, as well as to determine the farthest distance from the system at which the user can be to operate the door effortlessly.

The range of Bluetooth depends on its class and they are of three classes:

Class one has a range of $\mathbf{1 0 0}$ meters, class two has a range of $\mathbf{1 0}$ meters and class three has a range of less than $\mathbf{1 0}$ meters[11].

The range of infrared is about $\mathbf{1 m m}$. Data transmission rates on infrared are lower so it is regularly utilized for signaling instead of moving of data [12-15].

On testing the Wi-Fi range, a range of approximately 600 meters was obtained in an open field without barriers, and a range of about 45 meters was obtained in the presence of barriers (inside a building). This range is substantial and long enough for a user to open their garage door from the inside of their car.

The efficiency of this smart garage door was evaluated as $56.1 \%$. This value is as a result of the capacity of the motor used for the system.

\section{Conclusion}

The automated garage door was successfully designed, constructed and its performance evaluated. The stepper motor used for this project was found to be too powerful for the purposes it is required for. It is thus proposed that an electric motor of a much lower capacity should be used for future projects of this size. When the efficiency of the model system was extrapolated, and required torque calculated, the motor required need not be as powerful as calculated because a very wide allowance for power consumption was provided.

The Wi-fi range is quite substantial, and thus, the system can be operated from a good distance. Thus, a user can comfortably operate the system from inside his/her car. All in all, the system's power consumption is acceptable, but can be improved by using a motor of lower power rating. Nevertheless, a thorough assessment of the operational range of the Wi-Fi proved substantial and needs no improvement.

\section{References}

[1] N. Aidah Nabihah. (2016). “Design and Development of Low Cost Auto Gate System for House, Part 2,” No. January, pp. 0-15, 2016, doi: 10.13140/RG.2.1.3110.4080.

[2] T. Lehr and B. Benson. (2016). “Garage Door Security System,” California Polytechnic State University, 2016. 
[3] J. Kiran, B., Amarteja, L., Madarshareef, S., and Bindhusekhar. (2018). “Motion Based Automatic Garage Door Opener,” Int. J. Eng. Trends Appl., 5(2), 324-336., 2018.

[4] M. M. Ahmed, A. U., Masum, T. M., and Rahman. (2014). "Design of an Automated Secure Garage System Using License Plate Recognition Technique.,” no. 2014.02.03, pp. 22-28, doi: https://doi.org/10.5815/ijisa.

[5] A. Aman. (2018). “Original Research Paper Automatic Garage Door Opener,” Eng. Saswat Kumar Das Dr. Deo Raj Tiwari Ankit Pandey Anupam Sharma Dep. Mech., pp. 581-583, 2018.

[6] O. Oladunmoye, M., Oluwatomi, A. A., and Obakin. (2014). "Design And Construction Of An Automatic Sliding Door Using Infrared Sensor,” Comput. Inf. Syst. Dev. Informatics Allied Res. J., 2014.

[7] E. Irmak, E. Kabalci, and A. Köse. (2010). "Design and implementation of a computer interacted smart home system based on PLC,” in 4th International Conference on Application of Information and Communication Technologies, AICT2010, 2010, doi: 10.1109/ICAICT.2010.5612035.

[8] A. Murtala Zungeru and P. Obafemi Abraham-Attah. (2013). "A Digital Automatic Sliding Door with A Room Light Control System," 2013.

[9] A. N. Patil, R. B. Ranavare, D. V Ballal, and A. P. P. Kotekar. (2016). "Raspberry Pi Based Face Recognition System For Door Unlocking,” Int. J. Innov. Res. Sci. Eng., vol, 2016.

[10] A. Maier, A. Sharp, and Y. Vagapov. (2017). "Comparative analysis and practical implementation of the ESP32 microcontroller module for the internet of things,” in 2017 Internet Technologies and Applications, ITA 2017 - Proceedings of the 7th International Conference, 2017, doi: 10.1109/ITECHA.2017.8101926.

[11] Bluetooth SIG is, "Bluetooth Core Specification v5.1,” 2019.

[12] F. R. Gfeller and U. Bapst. (1979). “Wireless In-House Data Communication via Diffuse Infrared Radiation,” Proc. IEEE, 1979, doi: 10.1109/PROC.1979.11508.

[13] H. Folea, S., Bordencea, D., Hotea, C., and Valean. (2012). "Smart home automationsystem using Wi-Fi low power devices," in 2012 IEEE International Conferenceon Automation, Quality and Testing, Robotics, AQTR 2012, 2012, doi: https://doi.org/10.1109/AQTR.2012.6237775.

[14] U. Gfeller, F. R., and Bapst. (1979). “Wireless In-House Data Communication via Diffuse Infrared Radiation.,” in Proceedings of the IEEE., 1979, doi: https://doi.org/10.1109/PROC.1979.11508.

[15] B. Lehr, T. and Benson. (2016). “Garage Door Security System,” in California Polytechnic State University, 2016, doi: https://doi.org/10.1049/cce:20060601. 